\title{
High prevalence of obesity among women who enrolled in HIV prevention trials in KwaZulu-Natal, South Africa: healthy diet and life style messages should be integrated into HIV prevention programs
}

Handan Wand ${ }^{1 *}$ and Gita Ramjee ${ }^{2}$

\begin{abstract}
Background: In South Africa, poverty and the dual epidemics of HIV and tuberculosis underscore the need for prevention efforts for obesity. The aim of this study was to describe the prevalence of obesity in a cohort of South African women and discuss the implications for public health practices.

Methods: A total of 5,495 HIV-negative women from KwaZulu-Natal, South Africa enrolled in three microbicide trials during the period of 2002-2008 were categorised as normal weight (body mass index (BMI: 18.6-<25), overweight (BMl: 25-<30) or obese (BMI: 30+). Incidence of HIV and other sexually transmitted infections such as Chlamydia and gonorrhoea were also estimated and compared by BMl groups. Combined data was analysed using STATA 10.0.

Results: Approximately $70 \%$ of the sample population was classified as being overweight or obese. Older age and lack of education were determined to be significant predictors of obesity. Women who were 35 years or older were more than three times as likely to be overweight and more than 12 times as likely to be obese compared to the youngest group. The highest HIV and STI incidence rates were observed among those with $\mathrm{BMI}<25 \mathrm{~kg} / \mathrm{m}^{2}$ (normal weight) compared to women with BMI more than $25 \mathrm{~kg} / \mathrm{m}^{2}$ (8.1 and 19.8 per 100 person-year respectively, $\mathrm{P}<0.001$, both).

Conclusion: Effective obesity prevention strategies are needed to re-formulate HIV prevention programmes by incorporating healthy diet and life style messages to target those who are at highest risk not just for HIV infection but also for non-communicable diseases.
\end{abstract}

Keywords: Body mass index, Sexual risk behaviours, HIV, South Africa

\section{Background}

Obesity plays a major role in chronic non-communicable diseases, including type-2 diabetes, cardiovascular disease (CVD), and hypertension [1]. Globally, 1.3 billion people are estimated to be overweight or obese [2]. Obesity is not only affecting developed countries but is becoming an increasing problem in developing countries [3-5]. There has been a progressive increase in the prevalence of obesity in South Africa, particularly among women and young girls

\footnotetext{
* Correspondence: hwand@kirby.unsw.edu.au

${ }^{1}$ The Kirby Institute, University of New South Wales, Sydney NSW 2052, Australia

Full list of author information is available at the end of the article
}

[6-8]. A report published by the South African Medical Research Council (MRC) in 2007, cited that " $56 \%$ of adult women and $29 \%$ of adult men were overweight/obese, while $17 \%$ of children under the age of 9 years were overweight" [7,9]. The MRC also reported that "approximately 60 people die from obesity-related disease every day in South Africa". The primary reason for these high figures, particularly among black women, may be a number of misconceptions regarding the health risk of obesity, including the strong belief that increased body weight is an indication of a good state of health [10,11]. In addition, research conducted in the US indicates that access to and availability of nutritionally balanced food 
is associated with socio-economic status and structural factors, including the absence of accessible retailers of quality food in economically depressed or rural areas [12]. Similar phenomena could also be relevant to the South African situation.

South Africa is a developing country with a high prevalence of poverty [13]. Other factors such as violence, lack of education and inadequate services contribute to the increasing number of cases of non-communicable as well as communicable diseases [14,15]. South Africa bears the largest global burden of the HIV epidemic, with an estimated population of 5.7 million individuals living with the virus [16], and the third highest number of incident tuberculosis cases. The prevalence of obesity, particularly among black South African women, reflects globalisation, which is the primary driving force behind the changes in healthy diet and life style (i.e. nutritional transition) [17]. Developing and implementing obesity prevention programs will present numerous challenges in many South African communities where HIV, tuberculosis and poverty are pervasive, and access to a nutritionally balanced food supply is limited [3].

The HIV Prevention Research Unit of the Medical Research Council in Durban, KwaZulu-Natal, has been involved in several biomedical intervention clinical trials in HIV prevention. It has recruited more than 15,000 women. Counselling sessions associated with these trials educate women on how to protect themselves against HIV infection [18,19]. However, healthy diet and life style messages have never been incorporated into these programs.

The primary aim of this paper was to estimate the prevalence of obesity among a cohort of women, who enrolled in one of the three biomedical intervention trials during the period of 2002-2008 at clinical research sites in KwaZulu-Natal, South Africa. We also compared HIV seroconversion rates and other sexually transmitted infections across the women who were classified as normal, overweight and obese. Therefore implementing healthy diet and life style messages into these programs will create a unique opportunity (without an extra cost) to target those who are at most risk for obesity.

\section{Methods}

\section{Participants and design}

The current study included data derived from three biomedical intervention trials. Details of the main trials have been published elsewhere [20-22]. The present analysis included 1,485 women who enrolled in the Methods for Improving Reproductive Health in Africa (MIRA) trial of the diaphragm for HIV prevention (2002-2005). The Microbicides Development Programme (MDP) 301 study was a multi-centre, phase III, randomized, double-blind, and parallel group trial of a vaginal microbicide (2005-2008); we included 2,554 women who enrolled in MDP 301. The candidate microbicide Carraguard (PC-515), developed by the Population Council, was a non-contraceptive vaginally applied gel. Its efficacy against HIV infection was investigated in a randomized, placebo-controlled, double-blind, phase III trial (2004-2007). The present analysis included data from 1,456 women who enrolled in the Carraguard trial.

All protocols and informed consent forms were approved by the Biomedical Research Ethics Committee at the University of KwaZulu-Natal, as well as the various study-specific Institutional Review Boards.

\section{Measurements}

The majority of the demographic information was collected by face-to-face interview. Body mass index (BMI) $\left(\mathrm{kg} / \mathrm{m}^{2}\right)$ was calculated based on clinically assessed weight $(\mathrm{kg})$ and height $(\mathrm{m})$ at baseline and month 12. The current analysis considered only the baseline measurements as there was no notable change with regard to BMI during the follow up across the trials. WHO definitions were used to categorize women as normal weight (BMI: 18.5-24.9), overweight (BMI: 25-29.9) and obese (BMI: 30 and above). Age was stratified into 4-year categories: 18-24 years, 25-29 years, 30-34 years, and $35+$ years. Women were also categorized based on their self-reported level of education (less than high school vs. at least high school or higher) and employment status (regular income vs. none/irregular income).

\section{Statistical analyses}

Demographic and sexual history variables were described by BMI groups. We used logistic regression models to test for the effect of age groups, level of education and employment status in obese (versus normal weight) and overweight (versus normal weight) women separately.

Kaplan-Meier survival analyses were conducted to estimate the proportion of women acquiring HIV infection and STIs during the study. Seroconversion date was estimated as the midpoint between the first visit date at which the woman tested positive for HIV and the previous negative test date. Time to seroconversion was defined as the difference between the seroconversion date and the enrolment date.

Cox proportional hazard regression models were used to determine the association between baseline BMI and incidence of HIV and STIs. We also reported age adjusted analysis; however, since the primary sexual risk factors were not collected in a consistent way it was not possible to combine them across the trials. Therefore we did not perform multivariate analyses in this combined population. 
All analyses were conducted using STATA 10.0 (College Station, TX, USA).

\section{Results}

Respondents were described overall and across the BMI categories in terms of age, level of education and employment status (Table 1). Of 5,495 women, 1,790 (32\%) had a BMI less than 25 (normal weight), 1,739 (32\%) had a BMI between 25 and 29 (overweight) and 1,966 (36\%) had a BMI of 30 or more (obese). Overall, the median age was 27 (inter-quartile range [IQR]:22-37). The median age in the three BMI weight groups (normal weight, overweight, and obese) were 22 (IQR: 20-28), 27 (IQR: 22-36), and 34 (IQR: 26-40) years, respectively. Proportions of women reported completing high school were $36 \%, 30 \%$ and $23 \%$ for normal weight, overweight and obese women respectively; employment rates were reported as $15 \%, 20 \%$ and $22 \%$ for normal weight, overweight and obese respectively.

The data showed a significant age effect (Table 1). Women who were 35 years or older were more than three times as likely to be overweight and more than 12 times as likely to be obese compared to the youngest group (i.e. <25 years) [Odds Ratio (OR): 3.35, 95\% Confidence Interval (CI): 2.79-4.01 and OR:12.56, 95\% CI: 10.44-15.10 respectively]. Women who had less than high school education were approximately $50 \%$ more likely to be overweight or obese compared to those who had completed high school (OR: 1.47, 95\% CI:1.27-1.70 and OR: 1.59, 95\% CI: 1.38-1.83). Overweight and obese women were more likely to report a regular income compared to women of normal weight (OR: 1.40,
95\% CI: $1.14-1.72$ and OR: 1.61, 95\% CI: $1.32-1.96$ respectively).

HIV and sexually transmitted infection incidence rates were determined by BMI group during the study (Table 2). The highest HIV and STI incidence rates were observed among those with BMI $<25 \mathrm{~kg} / \mathrm{m}^{2}$ (normal weight) (8.1 and 19.8 per 100 person-year respectively) compared to women with BMI more than $25 \mathrm{~kg} / \mathrm{m}^{2} \quad(\mathrm{P}<0.001$, both). Adjusted and unadjusted hazard ratios (HR) and associated 95\% Confidence Intervals (CIs) are presented in Table 2. After adjusting for age, only those with a baseline BMI 25$29 \mathrm{~kg} / \mathrm{m}^{2}$ were more likely to HIV seroconvert compared to those in the BMI $30 \mathrm{~kg} / \mathrm{m}^{2}$ or more. The estimated relative risk of STIs during the trial was also progressively higher in the overweight and normal weight group compared to obese women.

\section{Discussion}

Our study confirms an extremely high prevalence of overweight or obesity in this reasonably large cohort of women. Approximately $70 \%$ of the women were categorized as being overweight or obese indicating an alarming health concern in this population. This is slightly higher than overall figures reported for South Africa, and is the highest found among other African countries [6-9].

Our study found approximately 50\% of the obese women were older than 35 years of age. This strong link between obesity and age suggests that it might be vital to discuss healthy diet and body weight issues at the same time as issues of sexuality and sexual risk with young women, before they start gaining weight at older ages.

Table 1 Distribution of demographics by (body mass index) BMI groups

\begin{tabular}{|c|c|c|c|c|c|c|}
\hline & \multirow{2}{*}{$\begin{array}{l}\text { Total } \\
\mathrm{N}=5,495\end{array}$} & \multirow{2}{*}{$\begin{array}{l}\text { Normal weight } \\
\text { (BMI:18.6-24.9) } \\
\mathrm{N}=1,790\end{array}$} & \multirow{2}{*}{$\begin{array}{l}\text { Overweight } \\
\text { (BMI:25.0-29.9) } \\
\mathrm{N}=1,739\end{array}$} & \multirow{2}{*}{$\begin{array}{l}\text { Obese (BMI: } 30+\text { ) } \\
\mathrm{N}=1,966\end{array}$} & \multicolumn{2}{|l|}{ Odds ratio $(95 \% \mathrm{Cl})$} \\
\hline & & & & & $\begin{array}{l}\text { Overweight versus } \\
\text { normal }\end{array}$ & $\begin{array}{l}\text { Obese versus } \\
\text { normal }\end{array}$ \\
\hline All women & $100 \%$ & $32 \%$ & $32 \%$ & $36 \%$ & - & - \\
\hline Age, median (IQR) & $27(22-37)$ & $22(20-28)$ & $27(22-36)$ & $34(26-40)$ & - & - \\
\hline$<25$ & $2203(40 \%)$ & 1,147 (64\%) & $694(40 \%)$ & $362(18 \%)$ & 1 & 1 \\
\hline $25-29$ & $908(16 \%)$ & $273(15 \%)$ & $316(18 \%)$ & $319(16 \%)$ & $1.91(1.59,2.31)$ & $3.70(3.03,4.52)$ \\
\hline $30-34$ & $700(13 \%)$ & 129 (7\%) & $241(14 \%)$ & $330(17 \%)$ & $3.09(2.44,3.90)$ & $8.11(6.41,10.26)$ \\
\hline $35+$ & $1684(31 \%)$ & $241(13 \%)$ & $488(28 \%)$ & 955 (49\%) & $3.35(2.79,4.01)$ & $12.56(10.44,15.10)$ \\
\hline \multicolumn{7}{|l|}{ Education level } \\
\hline At least high school & 1649 (30\%) & $644(36 \%)$ & $522(30 \%)$ & $452(23 \%)$ & 1 & 1 \\
\hline $\begin{array}{l}\text { Less than high } \\
\text { school }\end{array}$ & $3846(70 \%)$ & $1146(64 \%)$ & 1217 (70\%) & $1514(77 \%)$ & $1.47(1.27,1.70)$ & $1.59(1.38,1.83)$ \\
\hline \multicolumn{7}{|l|}{ Employment status } \\
\hline Yes & $1044(19 \%)$ & $161(15 \%)$ & $348(20 \%)$ & $433(22 \%)$ & 1 & 1 \\
\hline No & 4451 (81\%) & 1529 (85\%) & 1391 (80\%) & $1533(78 \%)$ & $1.40(1.14,1.72)$ & $1.61(1.32,1.96)$ \\
\hline
\end{tabular}


Table 2 Incidence of HIV infection and sexually transmitted infections by BMI

\begin{tabular}{|c|c|c|c|c|c|c|}
\hline \multirow[t]{2}{*}{ At enrolment } & \multicolumn{6}{|c|}{ HIV incidence (6.7 per 100 person year, $95 \% \mathrm{Cl}$ : 6.1-7.4 per 100 person year) } \\
\hline & $\begin{array}{l}\text { Crude incidence rate per } 100 \text { Person } \\
\text { Year }(95 \% \mathrm{Cl})\end{array}$ & p-value $^{\dagger}$ & $\begin{array}{l}\text { Unadjusted Hazard Ratio } \\
(95 \% \mathrm{Cl})\end{array}$ & p-value & $\begin{array}{l}\text { Adjusted }^{\ddagger} \text { Hazard R } \\
(95 \% \mathrm{Cl})\end{array}$ & p-value \\
\hline $\begin{array}{l}\text { Body Mass Index } \\
\left(\mathrm{kg} / \mathrm{m}^{2}\right)\end{array}$ & & $<0.001$ & & & & \\
\hline Obese $^{1}$ & $4.6(3.8,5.6)$ & & 1 & & 1 & \\
\hline Overweight $^{2}$ & $7.8(6.7,9.0)$ & & $1.70(1.33,2.17)$ & $<0.001$ & $1.36(1.06,1.75)$ & 0.015 \\
\hline \multirow[t]{2}{*}{ Normal $^{3}$} & $8.1(7.0,9.4)$ & & $1.76(1.38,2.25)$ & $<0.001$ & $1.19(0.92,1.55)$ & 0.185 \\
\hline & \multicolumn{6}{|c|}{$\mathrm{STI}^{\ddagger \neq}$ incidence (15.6 per 100 person year, 95\% Cl:14.6-16.6 per 100 person year) } \\
\hline $\begin{array}{l}\text { Body Mass Index } \\
\left(\mathrm{kg} / \mathrm{m}^{2}\right)\end{array}$ & & $<0.001$ & & & & \\
\hline Obese $^{1}$ & $10.9(9.6,12.3)$ & & 1 & & 1 & \\
\hline Overweight $^{2}$ & $16.6(15.0,18.4)$ & & $1.82(1.55,2.14)$ & $<0.001$ & $1.46(1.22,1.75)$ & $<0.001$ \\
\hline Normal $^{3}$ & $19.8(17.9,21.9)$ & & $1.55(1.31,1.83)$ & $<0.001$ & $1.40(1.18,1.66)$ & $<0.001$ \\
\hline
\end{tabular}

It is important to address the steady rise in the prevalence of obesity in South African women. In South Africa, poverty and the twin epidemics of HIV and tuberculosis mean that prevention efforts for obesity may not have the highest priority. However, evidence suggests that, just like in the developed world, obesity and its co-morbidities are adversely affecting the lives of South Africans and the consequent burden of disease contributes to the increasing cost of health care. We recommend identifying effective obesity prevention strategies and integrating them into HIV prevention and management programmes as a component of the interventions needed to enhance the overall health of the population. Implementing healthy diet and life style messages into upcoming HIV/AIDS prevention programs will be beneficial without an extra cost. However, large scale prevention efforts are needed to help control the epidemic. Recently, a survey (The South African National Health and Nutrition Examination Survey - SANHANES-1) was planned for 2011-2012 to evaluate the health status of South Africans for non-communicable diseases, particularly those associated with diet and life style [23]. Results from the SANHANES-1 will inform the size of the problem among South African men and women.

Our study has several limitations. First, the data used in this study were taken from a cohort of women who participated to HIV prevention trials. Therefore, there may be selection bias of women willing to engage in clinical trials such as the ones included in this study. Second, primary sexual risk factors were measured differently at different time points across the trials considered in this study. Therefore, we did not assess the variables that may have explained the relationship between body weight and sexual risk. Consequently, it is possible that being overweight and being at risk for HIV or STIs are due to unmeasured covariates which is not the scope of the current study. Finally, information on nutritional and/or physical activity status was not collected in these trials.

Nevertheless, this study found significant associations; the hazard ratios demonstrated reasonably large effect sizes indicating a strong signal regarding these associations. Finally, since this is a secondary analysis, we did not determine statistical power a prior to the study. Well-designed studies with adequate power are necessary to answer the predictors of the obesity among women in South Africa.

\section{Conclusions}

Current study presented evidence for unacceptable high rates of obesity among South African women and our study adds new evidence using data from more than 5,000 women; while while this group is at higher risk for noncommunicable diseases compared to women of normal weight, normal weight women were at increased risk for communicable diseases compared to those who were overweight or obese. New strategies are needed to reformulate existing HIV prevention and treatment programs by incorporating information on a healthy diet and lifestyle to produce holistic health and wellness interventions.

\section{Competing interests}

The authors declare that they have no competing interests.

\section{Authors' contributions}

Contributors GR was the principal investigator of all the trials from Durban clinical research sites. HW performed the statistical analysis. GR and HW interpreted and drafted the manuscript. Both authors read and approved the final manuscript. 


\section{Acknowledgements}

The authors would like to thank the MIRA, Carraguard and MDP 301 trials participants. Our thanks also go to Gates Foundation, The United Kingdom Department for International Development and the Medical Research Council and the US Agency for International Development. We also acknowledge the assistance of Dr Nathlee Abbai and Dr Brodie Daniels for assistance in the preparation of the final manuscript. The Kirby Institute is funded by the Australian Government Department of Health and Ageing, and is affiliated with the Faculty of Medicine, The University of New South Wales. The content of this publication is solely the responsibility of the authors and does not necessarily represent the official views of any of the institutions mentioned above.

\section{Author details}

'The Kirby Institute, University of New South Wales, Sydney NSW 2052, Australia. ${ }^{2}$ HIV Prevention Research Unit, Medical Research Council, Durban, South Africa.

Received: 5 March 2012 Accepted: 1 February 2013

Published: 21 February 2013

\section{References}

1. WHO: Fact Sheet; Obesity and overweight. 2003. http://www.who.int./ dietphysicalactivity/publications/facts/obesity/en (Last accessed August, 2012).

2. Obesity Task Force, World Health Organization: Global Strategy On Diet Physical Activity And Health: Obesity and Overweight. 2005. http://www.who. int/gho/ncd/risk_factors/overweight/en/index.html.

3. Puoane T, Steyn K, Bradshaw D, et al: Obesity in South Africa: the South African demographic and health survey. Obes Res 2002, 10:1038-1044.

4. Filozof C, Gonzalez C, Sereday M, et al: Obesity prevalence and trends in Latin-American countries. Obes Rev 2001, 2:99-106.

5. Rivera JA, Barquera S, Campirano F, et al: Epidemiological and nutritional transition in Mexico: rapid increase of non-communicable chronic diseases and obesity. Public Health Nutr 2002, 5:113-122.

6. Labadarios D, Steyn NP, Mgijima C, et al: Review of the South African nutrition policy 1994-2002 and targets for 2007: achievements and challenges. Nutrition 2005, 21:100-108.

7. Walker ARP: Epidemiology and health implications of obesity in Southern Africa. In Chronic diseases of lifestyle in South Africa: review of research and identification of essential health research priority. Edited by. Cape Town: Medical Research Council; 1995:73-86. Technical Report.

8. Senekal M, Steyn NP, Nel JH: Factors associated with overweight/obesity in economically active South African populations. Ethn Dis 2003, 13:109-1.

9. Stein K: MRC Report; Heart Disease in South Africa; Dept. of Medicine. at the medical research council: University of Cape Town \& Chronic Diseases of Lifestyle Unit; 2007.

10. Mvo Z, Dick J, Steyn K: Perceptions of overweight African women about acceptable body size of women and children. Curationis 1999, 22(2):27-31.

11. Ndlovo PP, Roos SD: Perceptions of Black Women of Obesity as a Health Risk. Curationis 1999, 22:47-55.

12. Freeman A, Fast F, Freeman A, Fast Food: Oppression Through Poor Nutrition, 95 Cal. L. Rev. 2221 (2007). McDonald's Corp: Pelman v; 2005. 396 F.3d 508 (2d Cir. 2005)

13. Bradshaw D, Groenewald P, Laubscher R, et al: Initial burden of disease estimate for South Africa, 2000. Cape Town: South African Medical Research Council. 2012. http://www.mrc.ac.za/chronic/cdlchapter7.pdf.

14. Vorster HH, Wissing MP, Venter CS, et al: The impact of urbanization on physical, physiological and mental health of Africans in the North West Province of South Africa: the THUSA study. South African Journal of Science 2000, 96:505-14.

15. Ball K, Mishra G, Crawford D: Which aspects of socioeconomic status are related to obesity among men which aspects of socioeconomic status are related to obesity among men and women? Int J Obes 2003, 27:394-403. doi:10.1038/sj.ijo.0802237.

16. UNAIDS: AIDS epidemic update 2009. Geneva: WHO; 2009. http://data.unaids. org/pub/Report/2009/JC1700_Epi_Update_2009_en.pdf.
17. Abubakari AR, Lauder W, Agyemang C, et al: Prevalence and time trends in obesity among adult West African populations: a meta-analysis. Obes Rev 2008, doi:10.1111/j.1467-789X.2007.00462.x.

18. Wand H, Ramjee G: Targeting the hotspots: Investigating spatial and demographic variations in HIV infection in small communities in South Africa. J Int AIDS Soc 2010, doi:10.1186/1758-2652-13-41.

19. Wand $H$, Ramjee $G$ : The effects of injectable hormonal contraceptives on HIV seroconversion and on sexually transmitted infections. AIDS 2012, 26(3):375-380. http://dx.doi.org/10.1097/QAD.0b013e32834f990f.

20. Padian N, van der Straten A, Ramjee G, et al: Diaphragm and lubricant gel for prevention of HIV acquisition in southern African women: a randomised controlled trial. Lancet 2007, 370:251-261.

21. McCormack S, Ramjee G, Kamali A, et al: PRO2000 vaginal gel for prevention of HIV-1 infection (Microbicides Development Programme 301): A phase 3, randomised, double-blind, parallel-group trial. Lancet 2010, 376:1329-1337.

22. Skoler-Karpoff S, Ramjee G, Ahmed K, Altini L: Efficacy of Carraguard for prevention of HIV infection in women in South Africa: a randomised, double-blind, placebo-controlled trial. Lancet 2008, 372:1977-87.

23. The South African National Health and Nutrition Examination Survey (SANHANES-1): 2011-2012. 2012. http://www.hsrc.ac.za/Document-4377. phtml.

doi:10.1186/1471-2458-13-159

Cite this article as: Wand and Ramjee: High prevalence of obesity among women who enrolled in HIV prevention trials in KwaZulu-Natal, South Africa: healthy diet and life style messages should be integrated into HIV prevention programs. BMC Public Health 2013 13:159.

\section{Submit your next manuscript to BioMed Central and take full advantage of:}

- Convenient online submission

- Thorough peer review

- No space constraints or color figure charges

- Immediate publication on acceptance

- Inclusion in PubMed, CAS, Scopus and Google Scholar

- Research which is freely available for redistribution 